\title{
UNA MIRADA SOBRE LA FÁBULA ESPAÑOLA DEL XIX. LAS FÁBULAS DE PASCUAL FERNÁNDEZ BAEZA
}

JOSÉ ENRIQUE MARTÍNEZ FERNÁNDEZ

\author{
Universidad de León ${ }^{1}$
}

\section{Resumen}

En el siglo XIX la fábula española mantuvo una fecundidad semejante a la del siglo anterior. Este artículo analiza las fábulas políticas y morales de un autor casi olvidado de dicho siglo, Pascual Fernández Baeza, que ocupó altos cargos en la Magistratura y publicó algunas colecciones de fábulas con una doble finalidad: la sátira política y la educación moral de niños y jóvenes fundada en principios tradicionales como la obediencia, el estudio y el amor al trabajo. Destaca la variedad rítmica de las fábulas, que son un excelente muestrario de las combinaciones métricas de su época.

Palabras clave: Fábulas políticas y morales, Fernández Baeza, sátira, educación, principios tradicionales, variedad métrica.

\begin{abstract}
During the 19th century, the genre of the fable maintained the success it achieved during the previous century. This study analyses the political and moral fables of Pascual Fernández Baeza, an almost forgotten author who held senior positions in the judiciary and who published a number of fables with a dual aim; to work both as political satires and as models of moral education for children and young adults, based on traditional values such as obedience and the importance of studying and loving work. The rhythmic variety shown by the fables particularly stands out as an excellent sample of the metric combinations of the time.
\end{abstract}

Keywords: Political and moral fables, Fernández Baeza, satire, education, traditional values, rhythmic variety.

Tras el temprano florecimiento de la fábula en la España medieval, los Siglos de Oro la relegaron a una presencia esporádica en obras teatrales, ascéticas y picarescas. “Reapareció de la mano de La Fontaine con las Fábulas morales (1781) de Félix María Samaniego, que fijó el modelo de la fábula española moderna: se escribirá en verso con la mayor variedad métrica posible y se buscará como cualidad primordial la ligereza narrativa" (Navas Ruiz, 1973: VIII). Un año después editaba Tomás de Iriarte sus Fábulas literarias (1782). El éxito de uno y otro autor y el aprovechamiento de sus

\footnotetext{
${ }^{1}$ Correo-e: jemarf@unileon.es. Recibido: 03-01-2013. Aceptado: 15-03-2013.
} 
fábulas en la enseñanza hasta tiempos no muy alejados de nosotros los ha convertido en los clásicos del género por excelencia. Si en el XVIII la fábula se integró fácilmente en la corriente utilitarista del momento, que defendía la función didáctica y moral del arte, en el siglo siguiente el género mantendrá un cultivo pujante:

Aunque se considera el siglo XVIII como el propio de la fábula, ésta tuvo su apogeo en el siguiente y entre 1800 y 1900 he contado un centenar de autores españoles con uno o más libros en su haber. Bastantes tuvieron varias ediciones y algunos para uso escolar se reimprimieron de modo tan prodigioso como el Libro de los niños, de Martínez de la Rosa, que pasó de las setenta ediciones (García Castañeda, 1986: 574).

Las razones del éxito las explica Navas Ruiz:

El siglo XIX fue extraordinariamente fecundo en fabulistas. Y no es extraño si se tiene en cuenta que, por su naturaleza moralizante y por su exacta observación de la realidad, la fábula se aproxima a la literatura costumbrista tan en boga entonces, y es sumamente apta para la crítica social, ideal de una gran parte de la literatura decimonónica. Por otro lado, a un nivel de sociología literaria, la fábula se convirtió en España en el instrumento ideal para mantener una educación religiosa y moral sobre bases tradicionales de la que muy pocos -los mejores por supuesto y no siempre- supieron remontarse para reflejar las inquietudes y las tendencias nuevas (Navas Ruiz, 1973: 17).

Juan Eugenio Harzenbusch, Miguel Agustín Príncipe y Ramón de Campoamor son los fabulistas del XIX que han suscitado mayor interés, pero fueron muchos los que escribieron y publicaron colecciones de fábulas. Por no hacer un tedioso listado de los mismos, me limito a citar a los que, en su Fabulario español, Sainz de Robles consideraba "dignos de mención":

El magistrado y senador del Reino don Pascual Fernández Baeza, que publicó, en 1852, una Colección de fábulas políticas y morales; el diputado general de Vizcaya e historiador del Señorío de Guernica don José Agustín de Rentería -1750 a 1826-, cuyas fábulas han sido publicadas -1923por el erudito Alonso Cortés en una colección escogida de Fábulas castellanas; el sacerdote y abogado, profesor de Religión y Moral de don Alfonso XII, don Cayetano Fernández, de la Academia Sevillana de Buenas Letras, autor de unas Fábulas ascéticas; el oidor de la Audiencia de Aragón y consejero de S. M., don Rafael José Crespo (1789-1849), que dedicó sus Fábulas y epigramas al ministro Calomarde; don Juan Pisón y Vargas, autor de unas Fábulas políticas y morales, muy alabadas por Núñez de Arce (Sainz de Robles, 1964: 17).

No escasea la bibliografía crítica sobre Hartzenbusch y Campoamor, pero, salvo excepciones, los demás han merecido escaso aprecio.

En la larga lista de fabulistas españoles del XIX figura, como hemos visto, Pascual Fernández Baeza, en buena parte olvidado, pero que en su época gozó de cierta consideración. Nació en Ponferrada en 1798, dentro de una familia de la nueva burguesía que disputaba el poder al Antiguo Régimen. Realizó sus primeros estudios en su villa natal, estudios que tuvo que interrumpir con la entrada en ella de las tropas francesas el 3 de enero de 1809, huyendo con su familia a las montañas vecinas. Los reanudaría en Monforte de Lemos. Cursó Derecho en Valladolid, concluyéndolo en 1819 y ejerciendo, a partir de ese momento, distintos e importantes cargos dentro de la Magistratura: Promotor fiscal de su villa natal a partir de 1821, Corregidor en Lugo, Magistrado en la Audiencia de Valladolid, Fiscal y ministro en la de Madrid 
nombrado en agosto de 1843, miembro del Consejo Real en 1853...; se jubiló siendo Vocal supernumerario del Tribunal contencioso-administrativo (García, 2008).

\begin{abstract}
Este berciano, de no genial, pero sí precoz y claro talento, de afable trato y palabra cariñosa y convincente, de risueña faz y educadísimas maneras, de actividad incansable y ejemplar integridad, de ideas liberales y militante activo contra el absolutismo de Fernando VII, fue un entusiasta empedernido del progreso de la provincia, a pesar de que -como tantos otros- vivió fuera de ella largo tiempo, pero a la que representó en el Congreso de los Diputados desde 1836, y en el Senado en 1851 (Martínez García, 1982: 326).
\end{abstract}

Murió Fernández Baeza en Madrid en 1860.

Este hombre de "vigorosa conciencia ciudadana" (Carnicer, 1984), es autor del Método práctico de sacar apuntes y formar extractos, claros y exactos del resultado de los procesos (1843), libro que en su tiempo hizo buen servicio a los auxiliares de Justicia; elaboró una muy celebrada Estadística criminal del territorio de la Audiencia de Madrid (1849), un reglamento de las cárceles de la Corte y una obra de gran empeño que dejó inacabada, Fundamentos de la Legislación. Fue hombre preocupado por cuestiones arqueológicas, hasta el punto de presidir durante algunos años la Academia española de Arqueología y Geografía. Literariamente, gustó de la poesía y publicó algunas composiciones en periódicos provinciales; en 1854 publicó en Ponferrada A Fabio. Epístola satírica en que se describen los vicios políticos y morales de la Corte, larga composición de 212 versos que citamos aquí porque coincide con la intención que movió la escritura de su Colección de fábulas políticas y morales, publicada en 1852, y de su Nueva colección de fábulas morales, (tomo II) que apareció en 1858. La primera dio fama al jurisconsulto, sobre todo por ser declarada de lectura obligatoria en las escuelas públicas.

A la fábula se le ha asignado, entre sus finalidades, la de la educación moral, por lo que desde el principio fueron consideradas muy útiles en la enseñanza, aspecto subrayado por títulos como Fábulas de la educación (1871) de Antonio Trueba y Carlos Pravia, Moral infantil (1876) de Manuel Osorio Bernard, El amante de los maestros (1894), de Andrés Codoñer, etc., etc. El éxito escolar de la fábula se prolongó durante buena parte del siglo XX. María Rosario Ozaeta anota que en las doscientas páginas del libro primero de las Lecturas graduadas, publicadas en 1953 por la editorial Luis Vives, hay cinco fábulas de Esopo, cinco de Samaniego, dos de Iriarte, dos de Hartzenbusch, dos de Antonio de Trueba y una de cada uno de los siguientes autores: Manuel del Palacio, Campoamor, Cayetano Fernández, Florian, Príncipe, Schmid y Fernández Baeza, y añade que igual ocurre con otros libros escolares, lo que muestra "la gran profusión, así como del carácter pedagógico y moralizante de la fábula, tanto en la segunda mitad del XIX como en la primera mitad -y a veces más allá- del siglo XX" (Ozaeta).

Como hemos adelantado, en 1852 publicó Fernández Baeza su Colección de las fábulas políticas y morales. Bajo el nombre del autor venía la siguiente anotación: "Presidente de la Sala de la Audiencia de esta corte, Senador del Reino, y antes constantemente Diputado por el distrito de Ponferrada". El prólogo a la colección es instructivo respecto a las circunstancias de composición, al entendimiento y finalidad de las fábulas y a la razón de su publicación. No parece -si nos atenemos a sus palabrasque Fernández Baeza tuviera en excesiva estima a la poesía en general. Al fin y al 
cabo sólo le dedicaba, como a ocupación menor, los escasos momentos de ocio de que disponía:

Siempre he considerado como un precioso tesoro el hábito del trabajo. Para no interrumpirle, desde mis primeros años acostumbré a emplear en estudios agradables los breves ratos que las atenciones de mi carrera me dejaban libres. Con el mismo propósito en los últimos tiempos dediqué al cultivo de las Musas aquellos momentos de que en los días de fiesta o vacaciones me permitían disponer mis deberes como magistrado, individuo del Congreso, y presidente de varias juntas.

Es, por lo tanto, ocupación esporádica la de la poesía, un género que no requería ni mucho tiempo ni la continuidad de otro tipo de obras: "composiciones ligeras" las denomina, es decir, leves, de escasa importancia, por lo que la fábula, aunque "ficción ligera y expresiva", le pareció, dentro de lo poético, más acorde con el viejo precepto ilustrado de "enseñar deleitando". Por otro lado, la fábula le parecería a Pascual Fernández Baeza, "modalidad muy concorde con el espíritu crítico, moralizante y aleccionador de su vocación jurídica" (Carnicer, 1984). Dos finalidades vio nuestro escritor en la fábula que la hacen más digna que el mero pasatiempo versificador: la moral, enseñanza dirigida a niños y jóvenes, y la satírica, encaminada a la actividad política, que conocía bien. De ahí el título de su colección y la división en dos partes, políticas y morales atendiendo a una y otra finalidad. Sigamos sus propias palabras:

En medio de semejantes ocupaciones no me era posible emprender ninguna obra de las que requieren profunda mediación y largo empeño, sino que debía reducirme a composiciones ligeras de las que se conciben y trasladan al papel rápidamente. Huyendo de la frivolidad, di preferencia a la fábula, ficción ligera y expresiva, cuyo principal objeto es formar el corazón de la infancia y de la juventud, imprimiendo con indeleble estampa máximas de sana moralidad y costosas lecciones de la experiencia. Obedecía también por este camino al instinto que naturalmente me inclina a fustigar con las armas del ridículo los muchos vicios de que nuestra sociedad política adolece: empleos ambos muy conformes a la solicitud de un buen patricio, y al carácter de un magistrado².

Si hacemos caso a don Pascual, sólo escribirá sus fábulas para recitarlas en familia (las morales) o entre los amigos (las políticas). Algunas se publicaron en el periódico Laberinto, y al leerlas "uno de nuestros literatos más insignes", nos dice, le animó a seguir escribiendo fábulas y, a instancia de otras gentes, a publicarlas.

La Colección de las fábulas politicas y morales de 1852 consta de dos partes, conforme al título; después de una pieza de introducción ("Los dos niños"), son 22 las fábulas políticas, a las que siguen cinco epigramas, y 48 las morales. La última, “Fábula verdad. La vida del hombre" no es propiamente una fábula, que antes ha definido como "ficción ligera y expresiva"; en cambio, la última es una "fábula verdad" que contrapone a las demás; el soneto -también en eso se distingue el poema, pues es el único de la colección- es una paráfrasis poética del tópico de la vida como río que en nuestra lengua acuñó Jorge Manrique. Las fábulas morales disfrutaron en 1953 de una segunda edición aumentada con siete fábulas nuevas: Colección de fábulas morales, "declaradas de texto para las escuelas", como expresa la portada.

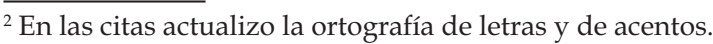


En 1858 apareció un tomo primero titulado Nueva colección de las fábulas políticas y morales de Pascual Fernández Baeza, “Senador del Reino y Consejero Real Jubilado”, y un tomo segundo, Nueva colección de fábulas morales, que figura como tercera edición aumentada; en este caso, bajo el nombre del autor se lee lo siguiente: “Consejero real jubilado, Senador del Reino, y antes de serlo, constantemente Diputado a Cortes por el distrito de Ponferrada, su patria"; este tomo segundo lleva exactamente el mismo prólogo que la colección de 1852, pero el tomo primero añade a aquel prólogo, que también incluye, algunas páginas más; en ellas aclara que fue Juan Nicasio Gallego (1777-1853), uno de nuestros últimos poetas neoclásicos, quien le incitó a la publicación de aquella inicial colección y que además valoró cada una de las fábulas, y cita las revistas y periódicos que se ocuparon de la colección de 1952: El Observador, La Esperanza, La Nación, La Época, La Ilustración, El Universo Pintoresco y La España, con firmas de Velisca (Seudónimo), Pedro Calvo Asensio y Eugenio Ochoa, que era Director de Instrucción Pública. Añade que se ocupó también de sus fábulas Joaquín María López en sus Lecciones de elocuencia impartidas en el Ateneo y publicadas en 1856. Todo ello le infundió estímulos para escribir nuevas fábulas, pero con una diferencia, a su parecer, de las anteriores:

Había hasta entonces prescindido del adorno de la descripción para concentrar más y más el pensamiento; pero me decidí a componer algunas fábulas descriptivas a fin de darles novedad, y agradar a los que anteponen a la concisión lo florido de las descripciones.

En efecto, así es en determinadas fábulas, en las que la descripción tiene algo de amplificatio, aunque ganan en plasticidad.

En el prólogo explica Fernández Baeza que el número de fábulas creció tanto que se vio obligado a publicar dos tomos, organizado cada uno de ellos en dos libros: el primero de cada tomo acoge las fábulas publicadas en 1852; el segundo libro, las fábulas nuevas; el primer tomo es todo él de fábulas políticas (38 fábulas más una pieza de introducción, "Los niños", y un epigrama) y el segundo de fábulas morales (80 en total, introducidas también por "Los niños"). Añade el autor dos cuestiones más: la primera, que las fábulas morales fueron declaradas "útiles para la enseñanza de la niñez" por Real Orden de 16 de mayo de 1853 y que con idéntico fin escribió en verso las oraciones de la iglesia (Padre Nuestro, Ave María, la Salve, el Credo, etc.) que unió a ellas en la Nueva colección; la segunda cuestión es que, antes de publicar las nuevas fábulas buscó la opinión crítica de calidad, en este caso de Antonio Alcalá Galiano y Eugenio Moreno López.

Una vez explicados los pormenores o circunstancias externas de las colecciones de 1852 y 1858, se trata de estudiar las fábulas políticas por un lado y las morales por el otro. Pero a unas y otras las encabeza la misma composición, “Los niños", como hemos reiterado, en razón de que en ella ofrece el autor la finalidad de sus fábulas: “También como el niño / a nadie reprendo: / los vicios tan solo / atacan mis versos: / y aquel que se ofenda / confiésase reo". 


\section{FÁBULAS POLÍTICAS}

"La fábula política española en el siglo XIX" fue estudiada parcialmente por García Castañeda (1986: 576-575). En su trabajo revisa, cronológicamente, las escritas por fray Ramón Valvidares, Cristóbal de Beña, Pablo de Jérica, José María Gutiérrez de Alba, Hartzenbusch y Fernández Baeza, para concluir que los ejemplos escogidos:

Muestran la vida española desde 1808 hasta mediados de siglo cuando gobiernan los "espadones" de turno, y porque reflejan el modo de pensar de quienes representan a esas "dos Españas" que se enfrentan en el XIX. He aquí el patriotismo a ultranza de un P. Valvidares absolutista, el combativo constitucionalismo de Beña y de Jérica, la verborrea demagógica de Gutiérrez de Alba, tan característica de aquella juventud democrática de los años 40, el escepticismo de un Hartzenbusch testigo del desgobierno de España durante medio siglo y, por fin, el liberalismo templado del magistrado Fernández Baeza, quien veía los problemas del país en términos legales y parlamentarios (García Castañeda, 1986: 575).

Las fábulas políticas de Fernández Baeza van dirigidas contra los vicios de quienes ejercen el poder (el gobierno, los diputados) y contra quienes lo jalean (los periodistas, pongamos por caso). Tienen, como es lógico, un punto satírico. Como indica García Castañeda, el magistrado Fernández Baeza fue siempre un liberal que con los años evolucionó hacia el moderantismo, algo que no puede seguirse por las fábulas al recogerlas sin orden y sin consignar la fecha de las mismas. Añade dicho estudioso:

Asuntos de varias es el despotismo, oprobio de los pueblos, aunque el déspota de hoy ya no es el rey, sino los gobiernos conservadores: unas yeguas a las que molesta un Lobo acuden al Tigre para que las defienda y éste acaba por devorarlas. La moraleja aclara: "Si es un mal la agitación / del gobierno liberal, / es la calma sepulcral / bajo la dominación / de un déspota, mayor mal" ("La yeguada").

La escena política reflejada aquí no ha cambiado con los años. Los candidatos siguen ofreciendo libertad y mercedes a sus electores y cuando llegan al poder no cumplen lo prometido ("El Pollo y las Gallinas"), los mejores puestos continúan en manos de trepadores y adulones, y el gobierno, que está encargado de dar leyes, es el primero en quebrantarlas ("El Lobo y el Zorro"). La moralidad pública no existe cuando los gobernantes se enriquecen a costa del erario ("El Lego y el Santo"), y tanto la oposición como la prensa, que tiene a su cargo el denunciar los abusos, dejan de hacerlo cuando les conviene. Así lo ilustra la fábula del perro que ladraba indignado a un gato que devoraba un jamón robado hasta que cayó un pedazo al suelo y el perro dejó de ladrar para comerlo: “A cuántos como el perro he conocido / que lanzando al gobierno ataques rudos, / un trozo de turrón los dejó mudos." (García Castañeda, 1986: 574).

Señala el mencionado crítico que el magistrado que fue don Pascual veía, en cambio, "la felicidad del país en la observancia de la ley y no en la revolución":

Advierte en contra de las coaliciones de partidos opuestos porque traen confusión y anarquía ("Los monstruos"), previene a los españoles contra la pasión partidista que hace olvidar los verdaderos intereses de la patria ("Los gallos"), y recuerda a los ambiciosos la vieja máxima de que la Revolución devora a sus propios hijos: "Todo el que suba al poder / por una sublevación, / debe esperar con razón / que le llegue a suceder / quien tenga igual ambición" ("Los Lobos").

La sátira del fabulista va dirigida contra el favoritismo y el mayor aprecio de la apariencia vana que de la virtud y el trabajo y contra los vicios y la corrupción del poder y el dinero. Siguiendo el hilo de las diferentes fábulas, Fernández Baeza critica a la sociedad y la comunidad política, que aprecian y premian más la apariencia que el 
mérito verdadero (“La abeja y el grillo", “El pollo y las gallinas”, “Las notabilidades”...), a los comprados o corrompidos por el poder o el dinero ("El perro y el gato", “El reclamo", "El perro rabioso"), censura los discursos vanos de diputados aparentemente serios ("Los grajos"), a los que abdican de votar en conciencia por miedo o cobardía o buscando el propio provecho ("El congreso de animales"), a los aduladores (“Los dos perros"), el falso patriotismo, la hipocresía de los que mandan, que hacen lo contrario de lo que dicen... Ataca al periodismo adulatorio del poder ("El reclamo") y al petulante a la vez que ignorante ("El mono y la zorra", "Los gozques”). La sátira cae contra el gobierno que quebranta la legalidad ("El lobo, el zorro"), contra la anarquía de cada uno por su lado ("Los colores"), contra los que, fiados de vanas teorías y proyectos, sin trabajo ni experiencia, pretenden el gobierno: "gran mal que a España aqueja", escribe el fabulista en "La receta", que subtitula "Cuento", pues cuento en verso es: un anciano experimentado hace ver a un joven inexperto y presuntuoso la necesidad del trabajo y la práctica previas a cualquier tarea de gobierno.

En las 16 nuevas fábulas políticas de 1958, la sátira es, a mi parecer, más directa contra los abusos de poder y contra el mal gobierno, contra el combate político cuyo pretexto es únicamente hacerse con el poder ("Los gallos”), contra la multiplicación de partidos para obtener algo del botín cuando no hay para todos (La langosta"), contra los gobernantes que resisten en el poder y llevan el país al desastre, como ocurre con el piloto que sin oír las advertencias del timón lanza su buque al naufragio ("El timón y el piloto"); contra la ambición política ("El ciervo”), etc. Pero, en efecto, como advertía García Castañeda, el magistrado don Pascual, liberal moderado finalmente, no creía en la revolución como redención del pueblo: al ejemplo anterior de "Los lobos" podemos añadir la fábula -cuento más que fábula- de "El arroyo", en el que una joven llena su cántaro mientras su plácida corriente no se convierte en "furioso torrente" que arrasa cuanto encuentra a su paso: “Como la bella joven, patria mía, / en las revoluciones / que bastarda ambición promueve y guía, / hallarás que dominan de igual modo / que al arroyuelo el sucio fango y lodo, / las sórdidas pasiones, / y destruyen, y arrasan las naciones".

Metido en la batalla política, el Senador del Reino y Diputado por el distrito de Ponferrada ¿añoraría alguna vez la tranquilidad de su villa natal? La larga fábula "El ciervo" es una amarga sátira de la ambición política. El animal que plácidamente campaba por valles y selvas es elegido "valido" del rey y acaba siendo odiado por todos, hasta el punto de caer del poder y no hallar donde cobijarse; y el fabulista exclama: “¡Ay quién de ti se fía, / oh política, y, ciego / por la ambición, tomándote por guía, / del campo deja el plácido sosiego!".

A las fábulas políticas siguen en la colección de 1852 cinco epigramas que participan del mismo tono satírico-político que las fábulas, atacando el cambio de principios según la conveniencia, la ignorancia de quienes rigen los destinos de la Patria, el medro de los habilidosos frente a los esforzados, etc. 


\section{FÁBULAS MORALES}

De acuerdo con el prólogo ya comentado de la Colección de las fábulas políticas y morales de 1852, si aquellas tenían una finalidad satírica, las morales, lógicamente, arbitraban una finalidad moral dirigida a jóvenes y niños. La fábula era acaso, como ya anunciamos, el género más propicio para instruir deleitando, para ofrecer una enseñanza moral por medio de una narración gustosa o amena.

Cuarenta y ocho son las fábulas de la mencionada colección de 1852. Al año siguiente, al publicar la segunda edición de las morales (Colección de fábulas morales) se añaden siete más y se prescinde de una, "Las gallinas"; son las que reitera en 1858, añadiendo 26 nuevas. En total son 80, por lo tanto, las fábulas morales publicadas por Fernández Baeza, número más que suficiente para darnos cuenta de cuánto le preocupaba al magistrado la formación moral de niños y jóvenes. De hecho, en muchas de las fábulas los propios niños se convierten en protagonistas, algo visible en títulos como "El niño y el pájaro", “El niño y el canario”, “El niño y el cazo”, "El niño y el ciervo", “Los niños y los galgos”, “Las dos niñas”, “El pequeño”, etc. En otros casos, la moraleja explicita su destinatario: "Si os dieren joh niños! / consejos villanos, / obrad como el perro / guardián del ganado" ("El lobo y el perro del ganado"). La misma métrica (romances, redondillas, seguidillas, versos tetrasílabos en algunos casos...) colaboraba en la pretensión de que la fábula fuera asequible y fácil de memorizar por su ritmo tradicional e incluso por su brevedad en muchos casos.

Dada la cantidad de fábulas morales no es fácil sintetizar los motivos que las mueven; en cualquier caso son, como es lógico, principios tradicionales, como la obediencia, el amor al trabajo, etc. Un buen número de fábulas se centran en la necesidad del estudio y la aplicación al mismo: "El niño y el canario", "Los niños y los galgos", "El premio o los dos niños" o "El golpe", que añade a las cualidades naturales (el genio) el estudio para lograr un buen resultado, etc. Otras, como “El pelícano y el tiempo" o "El camello y la hormiga", cercanas temáticamente, celebran el trabajo, el esfuerzo, el sacrificio y la constancia, virtudes que tarde o temprano acabarán dando fruto. En este ámbito algunas fábulas proponen trabajar en aquello de lo que se alcance algún fruto ("Las conchas", "Las dos niñas"), la unión de estudio y experiencia ("El teórico") y trabajar no para el presente sino para lograr la felicidad eterna ("El cerdo y el gusano de seda").

El cuidado y la prudencia en el obrar es la enseñanza que se extrae de fábulas como "El niño travieso", "Los gatos y el niño", "El galápago y la lagartija" o "La aldeana". El hacer el bien no sólo es conveniente, sino que suele tener su recompensa ("El oso y el perro de San Bernardo”, “Las niñas y el hortelano”); en este campo, hay que mostrarse agradecidos y leales con quien nos hace bien ("El gozque y el mastín", "El lobo y el perro de ganado"). En otras fábulas ("El feo", "El pequeño", "El tuerto" o "La cojera") se concluye con que es el valer y la hermosura interior del alma lo que importa, por encima de las apariencias físicas; otra enseñanza es que importa más el propio valer que el que se apoya en el valer de otro ("La hiedra y el avellano”), y más lo que uno es que lo que aparenta, como expresa la moraleja de "El rocín y el caballo". 
Algunas composiciones hablan de la necesidad de la buena amistad como ayuda para evitar peligros en la vida ("El perro de lanas y el cachorro de caza"), por lo que tal amistad hay que cuidarla, sin abusar del amigo, como en "La urraca y el perro de lanas" hizo aquella con el segundo.

Si las anteriores son propuestas positivas, otras fábulas hablan de vicios que el niño y el joven han de combatir, como la mentira ("El niño y el galgo inglés”), el orgullo y el engreimiento ("La cometa"), la presunción, la avaricia ("La comadreja y los ratones"), la gula desconsiderada, la envidia ("El perro y el gato", "La luna y los vapores"), las acciones traicioneras y engañosas ("El perro, la zorra y el lobo"), la ambición que lleva a querer destacar, sin formación suficiente, antes de tiempo ("El albillo agraz y la fresa") o a ilusionarse con salir de su "honesta medianía" ("Los niños baleares").

Capítulo importante en las fábulas de Fernández Baeza son las jóvenes, la formación moral de las jóvenes. No le podemos pedir al magistrado y fabulista que fuera un adelantado a su tiempo, un tiempo en el que la mujer desarrollaba su vida en el ámbito familiar y cuyo destino consistía en ser buena madre y buena esposa, sin autonomía personal ni laboral ni independencia económica. La educación, bajo el secular paraguas de la Iglesia, formaba mujeres piadosas que fueran expertas en "las labores propias de su sexo", según fórmula muy utilizada en la época. Nuestro fabulista vela por la mujer prudente, cautelosa, de modales dignos, atenta a la belleza interior más que a la externa. Al hilo de las fábulas que tienen como destinataria directa a la mujer, podemos establecer algunos grupos temáticos, según sus propuestas morales. En el primero y más abundante situaríamos aquellas fábulas que previenen contra el amor engañoso; la fábula más atractiva en este ámbito es "Las sirenas": con el eco odiseico de las sirenas y Ulises se previene a las jóvenes contra los cantos de sirena engañosos de quienes las adulan: "Inocentes, del canto fementido / de insidiosos amores, / y sus tonos traidores, / apartad, cautelosas, el oído". De igual modo, se previene a las confiadas en su experiencia ("La corona”). No es ajeno a nuestro tiempo el hecho de que la sociedad disculpe al seductor, pero denigre a la seducida: "Si alguna se abandona, / el mundo no perdona / su perdición, y achácale la culpa: / mientras al seductor se le disculpa" ("Los gatos con peste"). Más aún, es a la mujer a la que se culpa de los desmanes del hombre: “¡Cuántas jóvenes del día, / al erizo abierto iguales, / dan margen con sus modales / y gestos, a la osadía" ("Los dos erizos de castaño"). Otro tema es el del valor de lo natural e interior frente a lo artificioso y exterior ("El barniz"). Un tercer tema atañe a la mujer virtuosa: “Jóvenes, sed virtuosas: / inspiraréis puro amor; / y no, cual mariposas, / aficiones peligrosas, / fruto del brillo exterior" ("El niño y la mariposa"). Finalmente las actitudes de la mujer en el matrimonio inspiran otras fábulas, acaso las más curiosas y las que mejor muestran el lado conservador de don Pascual Fernández Baeza. El hogar como lugar propio de la mujer aparece en "Las dos primas": “¡Jóvenes! en el amor / de los hijos y el esposo, / y doméstica labor, / se halla el goce encantador; / no en el festín bullicioso". Al marido, en cambio, hay que dejarle suelto: "La que conservar quiera / un amante sincero, / no olvide por bien suyo / lo del niño y el ciervo", es decir, que no sujete al ciervo (el 
amante) como un carcelero, pues acabará huyendo buscando libertad. Es probable que "Las dos gallinas", de la colección de 1852, desapareciera en las ediciones siguientes por la propuesta de perdonar en el casado lo que a la casada no se le perdonaría: "Si un delirio cometieren los maridos, / sed prudentes, esposas; / buscadles cariñosas, / y prestos los veréis arrepentidos".

En resumen, don Pascual alaba a la joven prudente que cierra oídos a halagos y palabras engañosas, a la mujer cuya belleza natural no debe ser resaltada artificiosamente, a la mujer modosa, comedida, modesta, de ademanes honestos, a la mujer que no se confía, siempre prevenida contra los posibles engaños del hombre, y, en fin, a la mujer hogareña que halla la felicidad en el seno familiar.

\section{MÉTRICA}

La habilidad métrica de los principales fabulistas españoles ha sido generalmente reconocida, de Iriarte sobre todo entre los del XVIII, pues los recursos métricos de Samaniego, más monótonos y previsibles, "son inferiores a los de Iriarte: la rima es pobre, basada en múltiples ocasiones en verbos y adverbios; predomina la silva, que le permite gran libertad, y son frecuentes las estrofas de cuatro versos y los pareados" (Sotelo, 2000: 52). La riqueza rítmica de Tomás de Iriarte, en cambio, la han manifestado tanto los estudios de métrica española como los que versan sobre el fabulista canario. De Navarro Tomás son estas expresivas palabras:

El ejemplo de Iriarte debe notarse, no sólo porque ensayara una variedad de metros no igualada por ningún otro autor contemporáneo ni anterior a su tiempo, sino por el sentido artístico que, dentro del tono sencillo y familiar de sus fábulas, supo tener por guía al acomodar a cada ocasión el efecto rítmico más adecuado [...]. Sin inventar ningún verso que no tuviera precedente en español, contribuyó a restablecer modelos olvidados, a dar vida propia a tipos especiales que hasta entonces no se habían usado de manera independiente y a popularizar sus experiencias por todas las áreas del idioma (Navarro Tomás, 1974: 344).

“Iriarte consiguió en las Fábulas el repertorio métrico más rico de todo el siglo XVIII" ha consignado un editor de sus fábulas, que considera que el género permite mucha versatilidad rítmica (Prieto de Paula, 1992: 91). Acaso por eso, los fabulistas del siglo XIX se caracterizan, como Iriarte, por la variedad métrica de su producción fabulística, empezando por Hartzenbusch, pues "desde el amplio ritmo de la silva al alegre de la seguidilla, casi todos los versos y estrofas del español están representados en las Fábulas" (Navas Ruiz, 1973: XXII). En cuanto a Miguel Agustín Príncipe, él mismo certificó en el título la diversidad rítmica de sus composiciones y su interés por los aspectos métricos: Fábulas en verso castellano y en variedad de metros... precedida de un prólogo que contiene la historia de la Fábula desde Esopo hasta nuestros días y seguida de un "Arte métrica" (dos tomos, 1861-1862).

Pascual Fernández Baeza no les va a la zaga a los nombrados en variedad métrico-rítmica y en el intento de acomodar el ritmo a la materia grave o ligera de la fábula. Podemos decir que utiliza todos los metros que van del trisílabo al dodecasílabo, en las diversas combinaciones que la tradición métrica había ya experimentado. En 
este sentido no es Fernández Baeza un innovador, como no lo fue tampoco Iriarte, pongamos por caso. Ni lo fue ni podíamos esperar que lo fuera.

La única composición en versos trisílabos es "El niño, el perro y el gato", que, dada la rima asonante de los versos cuarto y octavo de cada estrofa, en la práctica lectora se convierten en una sucesión de versos hexasílabos en forma de romance o romancillo, como demuestra otra fábula, "El mochuelo", un romancillo hexasilábico cuya moraleja de doce versos trisílabos no es más que una configuración más airosa de los hexasílabos divididos en sus hemistiquios: “Lectores, / creedme: / a muchos / por serios / y darse / gran tono / guardando / silencio, / / les tienen / por sabios / y son ¿qué? / Mochuelos".

El verso de cuatro sílabas, utilizado como quebrado en poemas de versos octosílabos, no se empleó de modo independiente hasta el neoclasicismo y el romanticismo (Domínguez Caparrós, 1999: 428) y alcanzó “amplia representación con las fábulas La urraca y la mona y La ardilla y el caballo, de Iriarte" (Navarro Tomás, 1974: 335). Lo utilizó Fernández Baeza en estrofas de doce versos divididas en dos partes simétricas en cuanto a la disposición de las rimas. La división la marca la consonancia aguda entre los versos 6 y 12. Vemos tal estrofa duodécima en "El premio o los dos niños", donde todos los versos 6 y 12 de cada estrofa riman en -ón, y en "El lego y el santo" cuya disposición de rimas presenta esta forma: $-a-a-b-c-c-b$. La fábula "Los dos perros" presenta un juego de rimas más trabado: -abbac-deedc; tanto el verso corto como la disposición de las rimas reproduce rítmicamente la inquietud del perrito y su ladrido persistente: “Un doguito / le mostraba / a su dueño / duro ceño, / y ladraba / con furor, / hasta tanto / que veía / que atendido / su chillido / le decía: / 'Ladrador' ".

El verso pentasílabo lo usa Fernández Baeza combinado con el heptasílabo en las seguidillas, relativamente frecuentes. La seguidilla usada por nuestro fabulista es, sin excepciones, la llamada compuesta, es decir, la que a los cuatro versos tradicionales une un estribillo de tres versos, el primero y el tercero pentasílabos que riman en asonante, y el intermedio heptasílabo blanco. Indica Domínguez Caparrós que esta forma de seguidilla se extiende a partir del siglo XVIII (1999: 373), en el que alcanzó mucha popularidad. Fernández Baeza usa la seguidilla compuesta en nueve composiciones al menos, casi siempre breves, reducidas a una, dos o tres seguidillas: "La cometa", "Las apariencias", "El barniz", “Los gases", “El golpe”, "La modestia” y "El camello y la hormiga". Son, las de una sola seguidilla sobre todo, ejemplo de síntesis y escasez de acción.

Los demás versos de arte menor, hexasílabos, heptasílabos y octosílabos, los usa Fernández Baeza en variadas combinaciones. El romance es una de ellas. Los hexasilábicos o romancillos, de ritmo ligero y andadura ágil, los vemos en "El mochuelo", "El lobo y el perro de ganado", "La langosta" y "El perro rabioso"; en éste, con cierto alarde de ingenio, van alternando los estribillos "por fatalidad" y "por casualidad". 
El romance heptasílabo lo emplea en "El ciego y su sobrino", "El galgo", "El niño travieso", “Los gatos y el niño", "El niño y el ciervo", "La abubilla y el armiño", “El asno presumido" y “La abeja y el zángano.

El romance propiamente dicho, en octosílabos, aparece en fábulas como "La receta", "El niño y el pájaro", "Las dos golondrinas" y "La luna y los pájaros".

Fernández Baeza nos da buena muestra de distintas modalidades estróficas en versos de arte menor: pareados en "El feo" y "Las niñas y el hortelano"; redondillas en "La cola”, “El lebrel y el mastín”, “El niño y el canario” y otras catorce o quince composiciones más, lo que nos indica el aprecio por una forma que los poetas neoclásicos habían desechado y los románticos volvieron a recuperar; cuartetas en "El albillo agraz y la fresa”, "Las dos niñas" y algunas fábulas más; en quintillas se desarrollan fábulas como "La cojera”, "El teórico, “Las dos primas" y "La aldeana”, pero a la quintilla recurrió principalmente para la moraleja en fábulas dispuestas en otras modalidades estróficas: los romances de "El niño y el galgo inglés" o "Los dos alhelíes", por ejemplo, terminan con una quintilla; la fábula "Los dos gallos", en cuartetos endecasílabos, termina con esta quintilla: “Quien con violenta opresión, / abusando del poder / causa injusta vejación, / a los hombres de valer, / les da más grande opinión". Pero el fabulista berciano experimenta también con otras formas métricas más complejas como la octavilla y la décima. La octavilla aguda, en dos semiestrofas simétricas con pausa marcada, la practicó en "El rocín y el caballo" y en “El glotón" con una misma fórmula: $-a a b-c c b$, donde los vv. $4^{\circ}$ y $8^{\circ}$ terminan en aguda: era la misma que popularizó Espronceda en la "Canción del pirata". En cuanto a la décima, sólo la utilizó en dos fábulas: "La perpetua y la rosa" y "La araña".

El endecasílabo es, con mucho, el verso más usual del arte mayor, en muy diferentes combinaciones: pareados ("El oso y el perro de San Bernardo" y algunas fábulas más), tercetos encadenados ("El pólipo"), cuartetos y serventesios ("Los colores”, "Los dos gallos”, “El congreso de animales”, “El pastor”, “La hiedra y el avellano”...), octavas reales ("El avestruz y el ruiseñor", una sola octava).

Lo más frecuente es la combinación del endecasílabo con el heptasílabo en variadas modalidades estróficas: serventesios en "Los ochavos y las monedas de plata": $A b A b$. Otras combinaciones con rima consonante, todo un muestrario, son: $A b a B$ ("El ganso legislador"), $a B a B$ ("El perro y el gato", “El asno fanfarrón"), abaB ("La violencia"), aBAB ("El perro, la zorra y el lobo"), AbAB ("El timón y el piloto", "El lagarto y el zorro"), AbbA ("Las dos gallinas", "Las sirenas"), aBBa ("La abeja", “La envidia”), aBBA ("Los gozques”), aaBB ("Las alquitaras", “El gato, la zorra y el galgo", pareados pero dispuestos en forma de cuartetos, como "La mona", "Los gatos con peste" y "El mono y la zorra", en esta fábula con la fórmula $a A b B$ ). En cualquier caso, son combinaciones que se emplearon mucho tanto en el neoclasicismo como en el romanticismo (Navarro Tomás, 1974: 310 y 355). 
Combinación diferente es la de "El perro de lanas y el cachorro de caza", fábula que alterna heptasílabos (impares) y endecasílabos (pares), de modo que aquellos son blancos y los pares o endecasílabos, asonantados en -á-o, manteniendo por lo tanto, una estructura romanceada.

La silva, con su libertad o falta de disciplina formal, fue muy propicia para el desarrollo de cualquier tipo de asunto; la emplearon los distintos fabulistas y la usó también Fernández Baeza en "El convite”, "El arroyo”, “El cuervo”, “Los niños aleares, "La cigüeña y el mirlo" y "El pelícano y el tiempo".

Ocasionalmente emplea el dodecasílabo, sólo en "El ruiseñor y sus hijos", en serventesios.

De mayor originalidad son las combinaciones con rima asonante. Formas asonantes emplea Fernández Baeza en combinaciones de decasílabos y hexasílabos, algo que se da en "El milano y las palomas", "La cigüeña y el gorrión” y "El manzano y la castaña", con esta estructura a lo largo de cada composición: A b A b A b A b... Los impares son decasílabos y riman todos entre sí y los pares, hexasílabos, riman también entre ellos con rima diferenciada de los decasílabos. Por otro lado, los decasílabos llevan acento en tercera, sexta y novena sílabas (decasílabo anapéstico o de himno) y los hexasílabos en segunda y quinta (anfibráquico). Algunos ejemplos: “La cigüeña y el gorrión" se compone de 32 versos distribuidos por el sentido en cuartetos: los impares, decasílabos, riman todos en -é-a y los pares, hexasílabos, todos en -á-o; “El manzano y la castaña" es una larga fábula de 56 versos en la que los decasílabos o impares riman en -é-o y los pares o hexasílabos en -á-o; en "El milano y las palomas", los decasílabos o impares riman en -é-o y los hexasílabos o pares en en -á-o:

\footnotetext{
"Escuchad mi amistoso consejo" decía un milano,

No he podido contrastar el uso de formas métricas semejantes. Desde luego, el romanticismo había experimentado combinaciones variadas de ritmos y medidas. Pero no cabe duda de que la fabulística de Fernández Baeza, todo un muestrario de posibilidades, es muy rica métricamente, a la altura, probablemente, de los fabulistas anteriormente mencionados en este ámbito, en el que era difícil que el berciano no emulara a quienes le precedieron. Anteriormente citamos la fábula "El perro rabioso" en la que alternan los estribillos "por fatalidad" y "por casualidad". Me parece indudable que algo tuvo que ver en el asunto una de las más célebres fábulas de Iriarte, "El burro flautista", que reitera un mismo estribillo: "Por casualidad". En otra fábula, concretamente en "El grabador y su auditorio", se evoca a Iriarte y su conocida pieza "El gato, el lagarto y el grillo", escrita para satirizar el "estilo retumbante", y cuya característica es la rima esdrújula de todos sus 36 versos endecasílabos pareados, todo 
un alarde en ese sentido. En "El grabador y su auditorio", Fernández Baeza quiere plasmar "la charla altisonante de un retórico" y comienza recordando los versos del fabulista canario: “QQue no resucitara en este día / Iriarte, aquel hombre tan científico / en copiar el lenguaje, cual sabía / de ciertos animales específicos”; pero, a falta de Iriarte, lo hará él con ironía, burla y sátira contra quien defiende la tiranía de los Reyes, aunque aparentemente se oponga a ella. En la moraleja vuelve a nombrar al fabulista canario: “¿No encontráis en verdad en este prólogo, / los hombres que Iriarte pintó crítico, / del grillo y del lagarto en el apólogo, / no pensando en hablar como político?". Lo interesante, para nosotros, es la imitación métrica, pues en los servestesios de Fernández Baeza todos los versos pares tienen terminación esdrújula: “ «De la mar imitad el alzamiento, / vino a decir el orador lunático: / No sufráis dictaduras ni un momento» / Con todo el dictador aplaude enfático!". Como en Iriarte, lo raro e hiperbólico de la rima esdrújula contribuye a la burla ridiculizadora del "orador altísono pindárico".

En resumen, si no hay novedades métricas, sí hay cierta ostentación de una variedad con la que Fernández Baeza proporciona un buen muestrario de la mayor parte de las combinaciones rítmicas que un poeta de su siglo podía practicar.

\section{BIBLIOGRAFÍA}

Carnicer, R. (1984): “Un jurista ponferradino. Pascual Fernández Baeza”, Fiestas de la Encina (Ponferrada), 1984, 13 (incluido en Del Bierzo y su gente, Valladolid, Junta de Castilla y León, 1986, 55-56).

David Kossoff, A. et alii (coords.) (1986): Actas del VIII Congreso de la Asociación Internacional de Hispanistas I, Madrid, Istmo.

Domínguez Caparrós, J. (1999): Diccionario de métrica española, Madrid, Alianza Editorial.

Fernández Baeza, P. (1852): Colección de las fábulas políticas y morales, Madrid, Imprenta a cargo de C. González.

Fernández Baeza, P. (1853): Colección de fábulas morales, $2^{a}$ edición aumentada, Madrid, Imprenta a cargo de C. González.

Fernández Baeza, P. (1854): A Fabio. Epístola satírica en que se describen los vicios políticos y morales de la Corte, Ponferrada, Imprenta de Joaquín León Suárez.

Fernández Baeza, P. (1858): Nueva colección de las fábulas políticas y morales, tomo I, Madrid, Imprenta de M. Campo-Redondo.

Fernández Baeza, P. (1858): Nueva colección de fábulas morales, tomo II, $3^{\text {a }}$ edición aumentada, Madrid, Imprenta y Estereotipia de M. Rivadeneyra.

García Castañeda, S. (1986): “La fábula política española en el siglo XIX”, en A. David Kossoff et alii (coords.) (1986): 567-575. 
García, M. J. (2008): Pascual Fernández Baeza, León, Fundación Pedro Álvarez Osorio / Ayuntamiento de Ponferrada.

Martínez García, F. (1982): Historia de la Literatura Leonesa, León, Everest.

Navarro Tomás, T. (1974): Métrica española. Reseña histórica y descriptiva, $4^{\mathrm{a}}$ ed., Madrid, Guadarrama-Labor.

Navas Ruiz, R (1973): “Introducción” a J. E. Harzenbusch, Fábulas, Madrid, EspasaCalpe, Clásicos Castellanos, VII-XXV.

Ozaeta, Mª R., “Los fabulistas españoles (con especial referencia a los siglos XVIII y XIX)", http://213.0.4.19/servlet/SirveObras/01477398655704417654480/ p0000001.htm?mar... (Consultado en diciembre de 2012).

Prieto de Paula, Á. L. (1992): “Introducción” a T. de Iriarte, Fábula literarias, Madrid, Cátedra, 11-100.

Sainz de Robles, F. C. (1964): Fabulario español, Madrid, Espasa-Calpe (Austral).

Sebold, R. P. (1995): Historia de la literatura española. Siglo XVIII, 6, en G. Carnero (coord.), Madrid, Espasa-Calpe.

Sotelo, A. I. (2000): “Introducción” a F. M. Samaniego, Fábulas, Madrid, Cátedra, 13-142. 